\title{
Los Irisarri: fortuna e infortunio de una élite revolucionada (1755-1865)
}

\author{
The Irisarri: the fortunes and misfortunes of a revolutionized elite \\ (1755-1865)
}

Francisco Rodolfo González Galeotti

\begin{abstract}
Programa de Becas Posdoctorales en la Universidad Nacional Autónoma de México, Becario del Centro Peninsular en Ciencias Sociales y Humanidades, Mérida, Yucatán
\end{abstract}

*Autor a quien se dirige la correspondencia: petateandolahistoria2.0@gmail.com

Recibido: 01 de julio de 2021 / Aceptado: 25 de octubre de 2021

\section{Resumen}

$\mathrm{Z}^{1}$ presente artículo es una reconstrucción biográfica de Juan Bautista Irisarri y Antonio José de Irisarri. Ambos,

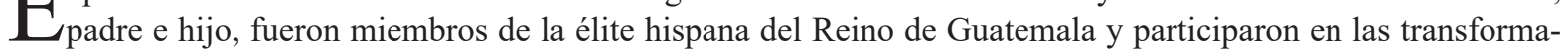
ciones sociales, económicas, políticas y culturales de la era de las revoluciones, es decir las transformaciones sociales y técnicas entre las décadas de 1790 y 1840 . El objetivo del estudio es analizar su rol protagónico entre la monarquía española y las repúblicas americanas independientes. Para ello, se echará mano de la metodología biográfica, historia de élites y familias notables, y el énfasis en sus facetas socioeconómicas (comercio, redes sociales y finanzas) para reflexionar sobre los orígenes de la clase burguesa.

Palabras clave: Redes familiares coloniales, élites hispanoamericanas, independencias latinoamericanas, orígenes de la burguesía

\section{Abstract}

$\mathrm{T}$

his article is a biographic reconstruction of Juan Bautista Irisarri and Antonio José de Irisarri. Both, father and son were members of the hispanic elite of the Kingdom of Guatemala and participated in the social, economic, political and cultural transformations of the Age of Revolutions, the social and technique transformations between 1790 and 1840. This study is focused on the protagonic role in the sociopolitical stage between the Spansh Monarchy and the independient american republics. To that end, it will be used the biographic method, the history of elites and notable families, and it will be emphasized the socioeconomic facets (Trade, social networks, finances) to make a reflection on the origins of the bourgeoisie.

Keywords: Colonial family networks, Spanish-American elites, Latin American independences, origins of the bourgeoisie 


\section{Introducción}

El presente artículo presenta las vicisitudes de dos actores pertenecientes a la élite del mundo finicolonial e independiente americano ${ }^{1}$. Las biografías de Juan Bautista y Antonio José de Irisarri servirán como pretexto para conocer las circunstancias históricas de las dos generaciones que protagonizaron la era de las revoluciones. Se propone estudiar la política y la economía desde la familia (Chambers, 2015), en un marco de sociabilidad (Bertrand, 2012) a fin de presentar una reconstrucción biográfica contextual. Así, se hilvanará cómo el comercio y política estaban en el centro de la palestra de los acontecimientos en el Reino de Guatemala, en el mundo Atlántico y en casi toda la América española. Esta reconstrucción servirá como punto de partida para esta pregunta: ¿Fueron las élites hispanoamericanas el molde de esa clase social globalizada que conocemos como burguesía?

La historiografía sobre el período de las revoluciones de independencia y las revoluciones atlánticas es bastante extensa. Sin embargo, por lo general dichos análisis suelen abordar los procesos a partir de cambios políticos, movimientos sociales, dinámicas institucionales y transformaciones en ideas y conceptos. Por otra parte, el abordaje de experiencias individuales se ha tratado desde una óptica conmemorativa o de la llamada historia de bronce. A fin de rebasar los límites de estas interpretaciones, el presente texto aprovechará elementos de tres métodos: la reconstrucción biográfica y la historiografía de familia y redes sociales. De esa forma será posible hacer una lectura que permita seguir el rastro vital de individuos concretos en contextos sociales y familiares específicos.

Como ha sido señalado por Bordieu, la reconstrucción de una vida no consiste en un relato unidireccional evolutivo con estaciones marcadas, anticipadas y cumplidas (2011). Estamos ante una experiencia, sí individual, pero enmarcada en un medio social y colectivo. No es asunto de ser cómplices de un relato de bronce sino de intentar presentar las tensiones, contradicciones y veleidades de la fortuna en una vida humana socializada.

1 Este artículo se deriva de la investigación doctoral que culminó en la la tesis titulada "Comercio franco y mercaderes en la Carrera de Guatemala (1740-1822)” de El Colegio de Michoacán (González Galeotti, 2020).
Para situar social e históricamente a los Irisarri es necesario ubicarlos en un marco concreto. Esto es, dentro de la élite hispana del reino de Guatemala, es decir una posición social privilegiada social y económicamente. De esa forma, aunque su sostén fuese su posición como clase dominante (Martínez Peláez, 2012), la expresión de ello se manifestó en los discursos de sangre, linaje y, para los vascos, el paisanaje o la identidad compartida de provincia (Hausberger, 2011). Ciertamente, la cristalización de ello fue la influencia o directamente control cargos institucionales en el aparato monárquico y, posteriormente, republicano (Palma Murga, 1985; Santos Pérez, 1999). Negar la sincronía de esos tres factores sería tapar el sol con un dedo en la lectura del pasado.

Identificar a los individuos en un marco social debe estar acompañada por su contexto relacional. Para eso la historiografía familiar es vital y en particular es útil retomar la noción de cambio generacional analizada para las familias notables de la América hispana. A grandes rasgos, indica como una generación nacida y constituida al calor de las reformas borbónicas es parte y/o se integra de las élites económicamente más poderosas de los territorios hispanoamericanos. La siguiente camada de individuos, aunque nace inserta en dichos círculos, experimenta los cambios revolucionarios del inicio de siglo, por lo cual participa la política del momento siguiendo el espiritu de la época para mantener su herencia de privilegios y posición socioecónomica (Balmori et al., 1984).

Por lo tanto, la familia es un prisma privilegiado para analizar la transición política del régimen monárquico al paradigma republicano independiente. Si bien la familia tiene una dimensión discursiva central en la época, su dimensión oeconómica patriarcal adquiere más relevancia al ser la fábrica de los capitales económicos y relacionales. La oeconómia literalmente se traducía en el gobierno de la casa, las relaciones y bienes para el bienestar doméstico, en el cual los jefes de familia imponían su voluntad sin cuestionamiento y solo teniendo como iguales a otros jefes reunidos para el bien común en las instituciones de la república, o sea ayuntamiento, cofradías, milicias (Zamora, 2012).

Las experiencias interconectadas de miembros de la élite son el mejor punto de partida para conocer cómo las experiencias vitales de un padre tienen eco en la vida de un hijo. Los negocios forjados por Juan Bautista fueron una herencia para su descendencia, que incluía no solo lo mercantil, sino también las relaciones sociales y vínculos. Pero, así como esa herencia 
fue una base que se podía ampliar en el curso de una generación, también tenía "fronteras" relacionales que delimitaban la capacidad de maniobra política de la nueva generación representada por Antonio José. En ese sentido, las situaciones contingentes de la era de las revoluciones, la diplomacia mercantil y el repliegue relacional sobre la red familiar es un factor derivado de la evolución y conformación de un patriarcado que influye en la experiencia vital de las jóvenes generaciones.

Finalmente, no hay que dejar de lado que, si bien la estructura familiar sirve como un esqueleto de apoyo, desde esta se amplían los márgenes de agencia individual gracias a otros participantes. Poco a poco se anudan vínculos y enlaces que contribuyen a ampliar, enriquecer y densificar el espacio relacional (Bertrand, 2012). De esa cuenta, aunque la estructura de la red relacional puede pesar en el individuo, es este quién a través de sus elecciones orienta el potencial relacional para fines concretos. La red relacional se convierte entonces en un arsenal que puede usarse para proyectos concretos, como emprendimientos mercantiles, decisiones institucionales y participación en revoluciones. Por supuesto, no se trata de elecciones ausentes de reveses. Las rivalidades mercantiles, cambios en coyunturas mercantiles, crisis políticas, burbujas financieras y guerras civiles, ponen a prueba la capacidad de maniobra de los individuos, sus límites y horizontes en que solucionar predicamentos. En una palabra, el devenir de la fortuna. Para ello veamos la historia de un padre y un hijo.

\section{Los Irisarri: el padre, el hijo}

Partimos entonces con el padre, Juan Bautista de Irisarri, un migrante vasco con un perfil y trayectoria no muy diferente a otros miembros de la élite mercantil de la América hispana. Él se destacó por posicionarse muy bien en el grupo de la élite ilustrada del Reino de Guatemala, ya que fue parte de la Sociedad de Amigos del País. Como otros hispanos, entre ellos los miembros del clan Aycinena, diversificó sus inversiones y apostó por negocios en coyunturas que parecían ser rentables. En ese sentido, destacó su inversión en la Mar de Sur u Océano Pacífico, espacio que a finales del siglo XVIII atestiguó la atlantización de océano Pacífico (Bonialian, 2017a, 2017b), es decir, la sostenida influencia económica del mundo At- lántico, en especial británica ${ }^{2}$. Para ello fue esencial su red familiar extendida en el reino de Chile. Allí su tío materno, Martín José Larraín Vicuña, fue fundador de los ochocientos, una red familiar muy poderosa que dominó la escena política chilena y clave para los negocios mercantiles de importación.

No obstante, Juan Bautista, se enfrentó a la resistencia y competencia mercantil, en especial de Juan de Isasi. La combinación de rivalidades, crisis políticas y desventura mercantil resultaron en su muerte en Jamaica y una serie de deudas por cobrar en varias de las provincias americanas de la fachada del Pacífico. A partir de 1805, su hijo, Antonio José, recorrió el continente saldando las deudas contraídas con su padre. No obstante, el joven se sumó a las revoluciones del cono sur y eso lo llevó a aventuras financieras y diplomáticas en la Europa posnapoléonica. Antonio no olvidó sus raíces en la Centroamérica independiente, ya que regresó al istmo y cerró filas en el bando centralista o servil durante la primera guerra federal centroamericana (1826-1829). Al ser derrotado, terminó exiliado en Sudamérica transitando entre Guayaquil, Bolivia, Chile y Nueva Granada mientras mantenía estrechos lazos con las élites ilustradas y literarias, y los círculos políticos conservadores centroamericanos y chilenos. En cierto sentido, siguió las huellas de su padre en los negocios, la cultura, pero con su distintivo sello personal en la política.

En conjunto, la fortuna de los Irisarri revela lo voluble del destino de las élites ilustradas en la era de las revoluciones. También es un muy buen ejemplo del rol que tuvieron sus redes de sociabilidad al manejar la dupla entre negocios y política durante la transición generacional de fines del siglo XVIII e inicios del XIX. Usando otras palabras, es la historia de las élites revolucionarias y revolucionadas.

\section{Juan Bautista de Irisarri, entre la notoriedad guatemalteca y la habitualidad continental}

Juan Bautista de Irisarri ha sido objeto de análisis de varios historiadores (Belaubre, 2005b; Bertrand, 2000, 2005, 2007a, 2007b; Browning, 1986; Fernández, 1993) por lo que a continuación solo referiré al-

2 Esto es la influencia mercantil de las potencias europeas, y anglosajonas en particular, en las plazas comerciantes americanas paralelas al Océano Pacífico, echando mano de mercadería manufacturada o bien de imitaciones de telas asiáticas. Esto fue correlativo a la "invasión" de manufactura europea que se introducía por el Atlántico, en general y el Caribe, a través del contrabando y los permisos de "comercio con naciones neutrales". 
gunos datos generales de su biografía ${ }^{3}$. Algunas obras mencionadas tratan al personaje como un arquetipo del entrepeneur decimonónico, sin embargo, al estudiar a fondo sus actividades mercantiles, esa imagen se diluye en el perfil del mercader borbónico, algo sobre lo que volveré más adelante.

Nativo de Aranaz, Navarra, Irisarri nació en 1755 y hacia la década de 1770 emigró de su región natal. ¿Por qué migró? Una particularidad de dicha área, como en todas las provincias vascongadas y Cataluña, es que la migración de hombres jóvenes era una constante. Las causas de dicha migración estaban fundadas en tres factores: condiciones socioeconómicas adversas, rotación de herencia y ocupación en diversos espacios sociales. El primer aspecto resulto de una crisis desde mediados del siglo XVIII en varios sectores productivos (agricultura, siderurgia, construcción naval) luego de un período de auge que tocó límite por la sobreexplotación de minifundios, arrendamientos y poca rentabilidad agrícola; carestías alimentarias y amotinamientos o machinadas; y falta de apoyo estatal a los astilleros atlánticos. La herencia, por otra parte, se caracterizó por ser un sistema en que la oeconomía vasca perpetuaba la unidad de la herencia de solares y casas familiares en favor de un descendiente, no importando fuese mujer u hombre. Ese sistema era un privilegio foral de los hidalgos vascos, ya que debían heredar el patrimonio o, de lo contrario, perdían su condición de hidalguia (linaje y apellido), privilegio para todas las personas en las vascongadas (García Giráldez, 1993).

Por lo general las familias vascas eran extensas y ante ese sistema de herencias muchos segundones debían salir adelante por medio de matrimonios, migrar a provincias españolas con más oportunidades o servir dentro de los cuadros institucionales de la monarquía. No eran expulsados de las redes familiares, sino que, por el contrario, ampliaban el alcance de las redes vascas gracias a la creación de contactos con individuos de la élite (García Giráldez, 1993). Sobresalieron en órdenes religiosas (jesuitas), cargos jurisdiccionales (magistraturas provinciales, gobierno municipal y cargos en Audiencias, etcétera) y militares (Imízcoz \&

3 John Browning ha dado algunos datos referenciales sobre su vida y es redactor de su biografía para la Real Academia de Historia de Madrid. Por otra parte, Michel Bertrand en varios artículos centrados en analizar su caso a la luz de las disputas sobre la integración y exclusión de mercaderes recién llegados del reino de Guatemala. Bernabé Fernández Hernández refiere algunos aspectos de su trayectoria económica. Finalmente, Christophe Belaubre es autor de su ficha biográfica en la Asociación para el Fomento de los Estudios Históricos en Centroamérica (AFEHC).
Guerrero, 2004). De esa manera, gracias a esos segundones, las redes de sociabilidad se expandían y fortalecían a través de la migración y la correspondencia.

Partiendo de lo anterior, Juan Bautista sin duda tendría contactos para salir de su pueblo natal, por lo que no es difícil suponer que a instancias de parientes radicados en Cádiz facilitaran su viaje ${ }^{4}$. En el puerto, como sucedía con otros migrantes, se habría integrado con alguna casa mercantil que comerciara con América (Arroyo, 2007; Martínez del Cerro González, $2006)^{5}$. De allí no sería difícil embarcar para América. En 1772, se lanza hacia Nueva España y en el trayecto trabó amistad con el alavés Manuel Ruiz de Zarate y Parrazar, quien le acompañó hasta Tehuantepec, donde el último se avecindó, y en años posteriores ambos mantuvieron correspondencia (Browning, 1986; Belaubre, 2005b).

Irisarri llegó a Guatemala en 1773 e inició negocios con dos coterráneos, Lazoaga y Ochandorena. A diferencia de otros españoles, inició su trayectoria en la Nueva Guatemala de la Asunción y es factible que haya aprovechado el auge de la producción del añil para afianzar sus negocios y crear una red de contactos en la nueva capital. El resultado de ello fue que en 1785 se casó con María de la Paz Espinosa y Barragán y Sotomayor, un matrimonio estratégico, pese a no contar con una gran dote para el matrimonio. Ella era hija de Bernardo Alonso y Barragán, abogado oidor de la Real Audiencia de Guatemala. Quiso la fortuna para él que su cuñada, Margarita, estuviese casada con José Ortiz de la Peña, también oidor y encargado de varios ramos de administración económica (Rubio, 1979). El concuño de Irisarri presidió en 1782 las instituciones borbónicas para el desarrollo del cultivo de añil (feria del añil y montepío de cosecheros), lo que le valió ser elegido como primer intendente de Salvador (Real Academia de la Historia, s.f.). Al mismo tiempo, Irisarri contactó con Juan Jacinto Herrera y Rivera, magistrado provincial y dueño de haciendas en Choluteca. De esa cuenta el navarro realizó dos préstamos cuantiosos entre 1785 y 1787 por cerca de 35000 pesos (Archivo General de Centroamérica [AGCA], Signatura A1.20, Legajo 928, Expediente 9421, Protocolo de Miguel González, folios 92v-93v. Obligación de 17871. $1 \frac{1}{2}$ pesos de Don Juan Jacinto Herrera a favor

4 En la primera mitad del siglo XVIII hasta 1767 varios vecinos de Guatemala apoderaron a Santiago de Yrizarri para representarles o realizar trámites por ellos en Cádiz. Este Santiago fue el mismo con el cual tenían vínculos los comerciantes de Antequera.

5 Tal es el caso de los Marticorena. 
de Don Juan Baptista de Yrizarri, 14 de mayo de 1785; AGCA, Signatura A1.20, Legajo 1344, Expediente 9835, Protocolo de Antonio Santa Cruz, folios 1v-2., obligación de 16777-7 1 1 2 pesos de Don Juan Jacinto Herrera a favor de don Juan Baptista de Yrizarri, 12 de enero de 1787).

Las alianzas tejidas a mitad de esa década le permitieron a Irisarri construir una red de sociabilidad anclada en los lazos institucionales por medio de su familia y los negocios. Eso les abrió las puertas a dos sectores económicos en auge: el añil y el mercado financiero. Asimismo, sus vínculos con las autoridades de la Audiencia sugieren que Juan Bautista podría haber conocido de cerca el manejo de la Real Hacienda y, por lo tanto, adquirir un juicio estratégico de la economía del reino. Paulatinamente sus operaciones mercantiles se fortalecieron gracias a una mayor vinculación con miembros de la élite mercantil guatemalteca. Por ejemplo, fue prestamista en 1788 del catalán Tadeo Piñol, importador de mercancías por el Caribe y dueño del asiento de esclavos (AGCA, Signatura A1.20, Legajo 1344, Expediente 9835, Protocolo de Antonio Santa Cruz, folios 75-76. Obligación de 1383 $1 / 2$ pesos de Don Juan Baptista de Yrizarri a favor de Don Tadeo Piñol y Muñoz, 12 de octubre de 1788). A veinte años de su llegada, nuestro navarro ya gozaba de una buena posición dentro de los círculos mercantiles, ya que fue participe de la creación del Consulado de Comercio de Guatemala en 1792 (Luján Muñoz, 1992; Woodward, 1981).

En 1794, luego de procrear a ocho vástagos, María de la Paz murió, probablemente por las continuas labores de parto. Para Juan Bautista esto implicó naturalmente una etapa de duelo. Sin embargo, en 1797, enlazó María Josefa Arrivillaga y Castilla Portugal. De esa manera se vinculó al clan Arrivillaga, a la sazón una de las familias criollas mejor posicionadas entre la élite gracias a que estaban dedicadas a la importación de ganado desde Nicaragua y Honduras, y su control en sus haciendas al sur y oriente de la ciudad (Sarazúa Pérez, 2007).

Paralelamente sus vínculos hacia Nueva España con Parrazar le facilitaron importar sillas y cojinillos para la curia (Machuca Gallegos, 2007). Asimismo, entre 1790 y 1792 exportó cerca de 1500 cabezas de ganado desde una hacienda que poseía en Chimaltenango hasta Oaxaca con su corresponsal Francisco Antonio de Goytia (Arrioja et al., 2017). Estos enlaces en la Nueva España eran esenciales ya que le facilitaron mantener una ruta esencial. Los oaxaqueños eran muy importantes ya que fueron el enlace con las casas mercantiles de Ciudad de México, como la casa Iturbe Iraeta, a la sazón también vinculada a la familia Aycinena de Guatemala (González Galeotti, 2020).

Sus negocios se extendieron a través de la fachada oceánica de la mar del sur a lo largo del continente americano. En Guayaquil tuvo el apoyo su sobrino, Francisco Xavier de Irisarri, dueño de dos bergantines que viajaban entre Perú, Guatemala y Nueva España, el Esclavo de María, el San Francisco Xavier y Nuestra Señora del Rosario (Rubio, 1977, pp. 298-309; Archivo Histórico del Guayas [AHG], EP/J 555). De hecho, para él exportaba cuerdas de guitarra y violín, lo cual en al menos una ocasión fue motivo de robo por salteadores (AGCA, Signatura A2.2., Legajo 197, Expediente 4015, Contra tres salteadores de caminos no conocidos que robaron una petaca con 486 gruesas de cuerdas de guitarra y violín, 1801). Asimismo, realizó negocios con parientes del lado materno en el Perú y en especial con los Larraín Vicuña de Chile, a quienes exportó productos del reino de Guatemala (hierro, alquitrán, añil, etc.) (Rubio, 1977).

\section{Un comerciante borbónico}

Como señalamos, en la década de 1790 Juan Bautista Irisarri era un individuo bien posicionado entre la élite guatemalteca. Para 1794, tenía al menos dos tiendas y el valor de sus mercancías rondaba los 896,000 pesos. Era un tipo bastante activo en el comercio del reino, pero ello no era casual ya que siempre mantuvo buenas relaciones con las autoridades. Muestra de ello fue su participación en los círculos ilustrados y en especial en la Sociedad de Amigos del País. Gracias a sus amistades con Alejandro Ramírez, secretario del Capitán General Domás y Valle, el oidor Jacobo de Villaurrutia y el futuro obispo de Chiapas Ambrosio del Llano, Irisarri se posicionó como un protagonista de la Ilustración en el reino. De hecho, gracias a su buena pluma se destacó en la Gazeta de Guatemala bajo el nombre de Guindalesio Chirimia, señalando, entre otras cosas, el hecho que la población indígena del país era la verdadera generadora de riqueza del reino (Belaubre, 2005b).

Irisarri tenía entonces el perfil de un mercader borbónico. Aprovechó sus vínculos con la burocracia real encargada de la Real Hacienda, creó una alianza estratégica con una familia bien posicionada, se asoció con individuos fortalecidos por el comercio y estrechó lazos con sus parientes que radicaban en otras provin- 
cias de la monarquía. Estas características fueron recurrentes entre individuos de la élite dedicados al comercio durante el auge del reformismo borbónico. Todo lo anterior facilitó a Juan Bautista el acceso al nervio de los negocios, es decir conocimiento e información que le permitieron tener un mejor entendimiento de las mareas mercantiles. Tal comprensión llevó a Irisarri a proyectar dos grandes esfuerzos económicos importantes: uno hacia el Atlántico y otro hacia el Pacífico.

El primero le permitió aprovechar el "comercio con neutrales" aprobado por la corona en 1797. Esta disposición surgió a raíz de las guerras europeas que llevaron a España a depender de naciones neutrales para movilizar productos tales como plata, papel, pólvora y otros productos esenciales en la balanza económica del Atlántico. De hecho, Irisarri era un importador de resmas de papel (AGCA, Signatura A1.15, Legajo 2530, Expediente 20159 Sebastián Melón sobre la declaratoria de la sentencia de arbitrios en los autos contra Juan Bautista de Irrisarri por unas resmas de papel, 1802). Una de esas naciones era Estados Unidos y de esa cuenta, Irisarri hizo tratos con mercaderes de Baltimore y Pennsylvania que comerciaron harina y telas con la Habana y Veracruz; con la Casa Torbes de Jamaica para importar mercancías por Trujillo, Honduras; y con el Perú a través del norteamericano James Yard en la embarcación San Juan Bautista que procedía de Boston (Fernández, 1993; Rubio, 1977). Para supervisar esos negocios Juan Bautista apoderó representantes en Cádiz, Veracruz y Trujillo (AGCA, Signatura A1.20, Legajo 766, Expediente 9259, Protocolo de José María Estrada, poder general de Don Juan Bautista de Irisarri a favor de Don Juan Felipe Xaurnaga vecino del Puerto de Veracruz, folios 6566v; 23 de mayo de 1800, poder general de Don Juan Bautista de Irisarri a favor de Don Francisco de Sosa en el Puerto de Trujillo y Don Thomas Urdiros, folios $79 v-80 v$; 7 de junio de 1800, poder general de Don Juan Bautista de Irisarri a favor de Don Antonio de Bernabé y Madero vecino de Cádiz, folios 184v-185v, 21 de noviembre de 1800). Y, a eso se sumó el hecho que el Capitán General José Domás y Valle, en 1799, dio su aprobación para las operaciones de Irisarri.

Sin embargo, esos negocios sufrieron varios reveses porque en 1800 se canceló el permiso de comerciar con neutrales. Cuando eso sucedió, varias de sus mercaderías fueron decomisadas en Nueva España, Perú y la Habana. Esa adversidad fue vista con mucha sorpresa por Gabriel de Iturbe en Ciudad de México, ya que señaló en una carta que otro mercader, Juan Fernández
Gil, había aprovechado la coyuntura y no había tenido ningún problema para movilizar sus hilados y telas hacia Guatemala (Archivo de la Compañía de Francisco de Yraeta [ACOFY] 2.1.34. carta de Ignacio Iturbe Yraeta para Francisco de Goytia folios 419-420v, 27 de diciembre de 1800, carta de Iturbe Yraeta a Goytia, folios 415-415v, 31 de diciembre de 1800). Para resolver la situación, Juan Bautista consideró viajar en barco desde Realejo a Acapulco, ya que entre 1798 y 1800 su barco Nuestra Señora del Carmen había hecho ese viaje (León Saénz, 2006), pero fue imposible. Por lo tanto, Irisarri acudió a la Casa Iturbe Yraeta y a su corresponsal en Antequera de Oaxaca, Francisco Antonio de Goytia, a quién apoderó (Archivo Histórico de las Notarías del Estado de Oaxaca [AHNEO], Libro 74, Protocolo de Joseph Álvarez, Poder especial de Francisco Antonio de Goytia, apoderado de Juan Bautista de Irisarri a favor de Gabriel de Iturbe e Yraeta, folio 329v, 23 de diciembre de 1800). Su objetivo fue obtener un amparo ante la Audiencia de México para que las mercaderías retenidas fueran liberadas para su venta.

Al parecer la balanza se inclinó a su favor cuando el Capitán General Domás y Valle salió bien parado en su juicio de residencia. Por lo tanto, el permiso concedido a Irisarri para negociar con neutrales no era contraproducente. Eso fue un alivio para Irisarri, ya que así podía vender las bretañas importadas y retenidas en Nueva España gracias a la Casa Iturbe. Sin embargo, las telas estaban sucias y húmedas, lo que no sólo desmejoró la calidad del producto, sino que redujo su valor (ACOFY, 2.1.38 Carta de Gabriel Iturbe Yraeta para Juan Bautista de Irisarri, folios 163-164, 24 de octubre de 1801, Carta de Gabriel Iturbe Yraeta a Juan Bautista de Irisarri, folios 221-222, 25 de noviembre de 1801) ${ }^{6}$. Al final, se decidió que las mercancías se enviarían a Guatemala por medio de Goytia. Para ello, el navarro extendió tres libranzas para realizar los pagos a través de Iturbe Yraeta (AHNEO, Libro 74, Protocolo de Joseph Álvarez, Poder especial de Francisco Antonio de Goytia, apoderado de Juan Bautista de Irisarri a favor de Gabriel de Iturbe e Yraeta, folio 329v, 23 de diciembre de 1800).

No obstante, lo peor estaba por llegar. La compañía de Vértiz, donde Iturbe depositó el dinero de Juan Bautista, quebró por malos manejos (Suárez Argüello,

6 Originalmente fueron $118.183 .4 \frac{3}{4} 4$ pesos que se redujeron por la mala calidad a 105589.4 pesos, aún más reducidos por los gastos de transporte y el pago la Casa de Moneda de Guatemala (67.526) a $13.199 \frac{3}{4}$ pesos. 
2007). De esa cuenta, su dinero quedó estacionado en Nueva España. Luego, en 1803, la Corona le revocó al navarro el permiso para comerciar con los norteamericanos, aunque por fin levantó el embargo de las mercancías (Fernández, 2003). Pero el obstáculo más grave fue la animadversión proyectada por Juan Antonio de Isasi, desde dentro del Consulado de Comercio de Guatemala, ya que fue el principal instigador de los obstáculos contra el navarro en la Audiencia de Guatemala (Bertrand, 2007b). Es posible que la rivalidad radicara en que Isasi tenía parientes y socios en Veracruz por lo que los negocios de Irisarri representaron una competencia que no podría tolerar. En todo caso, la combinación de la retención del dinero por la quiebra, pero sobre todo la rivalidad de Isasi, llevó a la quiebra del navarro.

Un cantar diferente fue su proyección hacia el Océano Pacífico. Allí trabajó en habilitar la costa sur del Reino, específicamente en Sonsonate, como puerto de embarcaciones de gran calado para que atracaran y estimular el comercio. Por ello, en 1797 propuso poblar esa jurisdicción con los caribes negros (garinagu), recién asentados en la costa norte del reino (por Omoa), para hacer productiva la tierra. Aunque esa idea no se aceptó, mantuvo la intención de colonizar el área de Acajutla para pescar y producir sal. En función de ese proyecto adquirió y habilitó una hacienda, La Soledad hacia 1800. Pero debido a los recurrentes viajes entre Nueva Guatemala y Sonsonate su salud desmejoró (Belaubre, 2005b; Dym, 2006; Woodward, 1981).

Por otra parte, como ya se indicó, tuvo actividad mercantil a lo largo del Pacífico. Por ejemplo, en 1798 cuando se autorizó el comercio recíproco entre Sonsonate y San Blas, en Nueva España, envió su embarcación N.S. del Carmen. Gracias a ello traficó aguardiente, vino, acero, almendras, aceitunas, aceite, cera de Habana, ropa y efectos de Castilla y China (León Saénz, 2006). Naturalmente la navegación se extendía hacia el sur, tal cual como se ha indicado antes, ya que se incluía a los puertos de Guayaquil, Callao, Valparaíso, comerciando con alquitrán, brea, bálsamo, madera, hierro, azúcar y añil (s.d. Gazeta de Guatemala, $\mathrm{N}^{\circ}$ 203, tomo V, folio 464, 11 de mayo de 1801; Rubio, 1977, citados por de León Saénz, 2006).

Pese a la estabilidad mercantil en la fachada del sur, las desventuras atlánticas marcaron el destino de Juan Bautista. En 1805 murió en circunstancias peculiares, ya que al parecer su cuerpo estaba en Kingston, Jamaica y no en Guatemala. Quizá intentó expandir los negocios con casas angloamericanas que apenas había iniciado durante el comercio con neutrales (AGCA, Signatura A1.20, Legajo 770, Expediente 9263. Transacción sobre la negociación del bergantín de guaquero y Balandra Gorrión entre apoderados de los síndicos de acreedores de la Casa de Dubue y Forves en la Ciudad de Kingston, Jamaica y los albaceas de Juan de Irisarri, folio. 38-55v, 20 de mayo de 1811) y dar solución a sus problemas mercantiles importando productos británicos. En todo caso, a su muerte, fueron su viuda e hijos quienes vivieron la urgencia de resolver sus deudas en Guatemala, Nueva España, Perú y Chile.

En términos generales, Juan Bautista de Irisarri fue un individuo borbónico. Migró y se afianzó gracias a vínculos de paisanaje, su red de sociabilidad con la burocracia real y la élite ganadera. Como sus coetáneos diversificó sus capitales relacionales, al ser parte de la élite oligárquica de Guatemala; y económicos, al invertir en varios sectores (ganadería, agricultura, comercio, crédito). Aprovechó el comercio con norteamericanos y británicos algo propio de la lógica mercantil hispana en la coyuntura, pero no desaprovechó hacer negocios con sus familiares y casas mercantiles a lo largo de la fachada pacífica del continente americano. Lo que distinguió su derrotero fue que sus grandes proyectos naufragaron a la deriva en múltiples eventos desafortunados.

\section{Antonio José de Irisarri, el énfant terrible de la generación patriota}

Antonio José de Irisarri, El cristiano errante (1961), fue el hijo criollo de Juan Bautista de Irisarri. Al igual que su padre ha sido objeto de estudio por varios académicos (Batres Jauregui, 1896; Browning, 1986; Donoso, 1966; Zúñiga Diéguez, 2020) aunque el énfasis de sus trabajos ha sido para su impronta literaria y diplomática. Es, por lo tanto, necesario destacar su dimensión económica.

A diferencia de su padre, su vinculación a los negocios fue circunstancial y no tanto el resultado de una carrera mercantil. Lo notable, es que fue heredero de un amplio bagaje ilustrado, como podía esperarse de la nueva generación criolla de la élite guatemalteca del reino de Guatemala. Tal como El hombre de la situación (Payno, 1861) fue educado por los betlemitas, con posiblemente su tradicional rigor. Su madre, introdujo las bases de la devoción católica, lo que se 
traduce en las bases fundamentales de la cosmovisión criolla, y que fue parte de la educación de la familia nuclear. Finalmente, como otros niños privilegiados, tuvo un profesor particular de lenguas (Batres Jauregui, 1896). Por supuesto, al ser el primogénito tendría que estar cerca de su padre y sus círculos ilustrados, pese a que solo recordase su severidad de carácter (Browning, 1986). Ahora bien, sus andanzas en los negocios comenzaron en mayo de 1805 , cuando inicia un recorrido que lo lleva de cobrar deudas de su padre y le llevaran a los entresijos de las finanzas revolucionarias.

Inició el camino yendo hacia a Nueva España con un fuerte contratiempo, ya que decidió viajar por mar desde Sonsonate hasta Acapulco, pero su bergantín fue secuestrado por la Kitty, un barco inglés. Logro acordar su libertad con el capitán británico, regresa a Acajutla y reinicia su expedición aprovechando el camino real hacia Nueva España. Poco a poco se encontró con varios individuos íntimos o conocidos de su padre, es decir exploró la red de sociabilidad de su padre. En Chiapas, recibió los contactos recomendados de abogados de la Real Audiencia de México, gracias al Obispo Ambrosio del Llano, amigo de su padre y socio de Juan Bautista de Marticorena, segundo exportador de añil del Reino (Belaubre, 2005a; Archivo Histórico Diocesano de San Cristóbal de las Casas [AHDSCC] Ramo Correspondencia, Expediente 60, Carpeta 5139, Carta de Antonio José de Irisarri a Ambrosio el Llano, México 25 de mayo de 1806; Carpeta 5140, Carta de Antonio José de Irisarri a Ambrosio del Llano, 9 de agosto de 1806). En Tehuantepec, fue recibido por Manuel Parrazar, ya todo un hacendado en Niltepec. En Antequera de Oaxaca fue hospedado por la familia de Simón de Larrazábal, tío de Antonio de Larrazábal, elegido a cortes en 1812 y su tío por parte de su madrastra. Allí se enamoró de la hija adoptiva de su anfitrión a quién solo conocemos por el sobrenombre que le puso José Antonio: Dorila (Irisarri, 1961)

En la Ciudad de México fue recibido por el guipuzcoano Gabriel de Iturbe, cabeza de la casa comercial Iturbe-Yraeta. Tanto Iturbe como Irisarri buscaron abogados que les representaran en el juicio por el dinero de Juan Bautista, retenido por la quiebra de Vértiz.

El abogado de Irisarri era Agustín Pomposo Fernández de San Salvador, jurisconsulto de gran reputación y conocido en su época como escritor. El de Iturbe era Nicolás de Larragoiti, cura de la catedral, como Fernández, destacado jurisconsulto, y además "goloso de alto renombre", según recuerda Irisarri (Browning, 1986, p. 21).
Antonio José pasó cerca de diez meses en la capital novohispana. Al parecer, Iturbe le ofreció una de sus hijas en matrimonio a cambio de pagar la suma adeudada $(120,000$ pesos), pero el joven rechazó la oferta y solo obtuvo un $70 \%$ del monto litigado (Browning, 1986). Por otra parte, aprovechó los contactos de su padre, en especial de antiguo oidor Antonio de Villaurrutia para publicar poesía en el Diario de México con el seudónimo Dionisio Yraeta Rejón (Zúñiga Diéguez, 2020).

No satisfecho con ese resultado, el guatemalteco regresó a Antequera, donde estaba su prometida. Estando allí, Iturbe mantuvo comunicación y le informó de un cajón a su nombre recogido en la aduana de ciudad de México (ACOFY, 2.1.43. Carta de Gabriel de Iturbe Yraeta a Antonio José de Irisarri, folio 249, 22 de noviembre de 1806, ). A inicios de 1807, Irisarri debe regresar al reino de Guatemala nuevamente, mientras Iturbe le informó del avance del proceso judicial. Huelga anotar que el guipuzcoano estaba harto del juicio por la dilación de la Audiencia, el virrey, y la Real Hacienda y por lo tanto esperaba una solución definitiva (ACOFY, 2.1.43. Carta de Gabriel de Iturbe Yraeta a Antonio José de Irisarri, folio 348v-349, 25 de febrero de 1807). Irisarri pasó por Ciudad Real de Chiapas, siendo recibido por Ambrosio del Llano, antes de dirigirse a la capital del reino y embarcar a Sudamérica en Acajutla.

La cobranza de deudas continuó en Perú y Chile en 1808 (Irisarri, 1961, pp. 231-156). Para ello aprovecha la embarcación de su primo Francisco Xavier de Irisarri, la San Francisco de Asís, que sale desde Acajutla hasta el Callao en un viaje de 87 días (Fernández, 1993, p. 339). Luego de pasar una temporada en Perú, se traslada a Chile, donde conoce a sus primos, los Larraín de Santiago de Chile. Con ellos decidió fortalecer su alianza familiar al casarse con su prima María Mercedes de Trucíos y Larraín, al tiempo que se enteró de la muerte de su prometida oaxaqueña. Quizá los prospectos de reforzar sus lazos con familiares bien posicionados en una plaza mercantil fuerte en lugar de una provincial habrían estimulado su decisión matrimonial.

Desde 1811 , se unió a la causa patriota chilena junto a sus familiares tomando un fuerte protagonismo en la independencia de Chile. De acuerdo con Chambers (2015), fray Joaquin Larraín, representante del clan, señalaba que: "Mi familia sostiene todas las presidencias: yo, presidente del Congreso; mi cuñado 
el ejecutivo; mi sobrino la Suprema corte. ¿Qué más podríamos desear?" (pp. 3, 11-17).

En 1814 Irisarri fue director supremo de Nación de carácter interino, cristalizando así la amalgama de intereses políticos y familiares (Browning, 1986). Empero, cuando al año siguiente los realistas triunfan sobre los patriotas chilenos, debe refugiarse en la provincia de Mendoza de las Provincias Unidas del Rio de la Plata. Por ese motivo viajó a Gran Bretaña a realizar estudios, pero al mismo tiempo apoya a la causa política de Buenos Aires e intercede entre el gobierno de Bernardino de Rivadavia, gestionando tratos con los británicos y como embajador por Chile luego del triunfo patriota ya a inicios de la década de 1820 (Browning, 1986).

Su gestión diplomática fue controversial por decir lo menos. Para empezar, tenía un muy alto concepto de sí mismo, al punto de menospreciar a sus coetáneos del cono sur al considerarles poco aptos para el trato "civilizado" con los británicos. Al punto de indicar que "El mayor trabajo que tengo en estas circunstancias es del no dar a conocer a estos señores el concepto que merecen sus talentos, por lo cual me veo precisado a callar cuando me escriben o hablan sobre sus impertinencias ..." (Carta de Don Antonio José de Irisarri a Don Bernardo O'Higgins, Anales de la Academia de Geografia e Historia, 4, 1937, pp. 458-460).

¿Por qué esa actitud? En parte podría tratarse de un asunto de ego, finalmente era miembro, por partida doble, de núcleos de la élite hispana en América que siempre habían destacado su primacía sobre otros grupos sociales o políticos. También podría tratarse también de los límites de la red de sociabilidad que había heredado y hallarse en la frontera de los vínculos sociales conocidos y la incompatibilidad tener sinergia con otras élites.

Aunque, las polémicas no se restringieron a su carácter, ya que involucraron operaciones financieras clave para las revoluciones. Por ejemplo, el empréstito de un millón de libras esterlinas con la compañía Hullet Brothers en 1822 indignó al congreso chileno (Browning, 1986; Dawson, 1990). Luego, se trasladó a Paris para comprar una goleta y obtener el reconocimiento diplomático de parte de Francia (Dawson, 1990). Naturalmente no fue el único latinoamericano allí, ya que todas las naciones independientes enviaron agentes para obtener préstamos que fueron objeto de especulación en la bolsa londinense (Dawson, 1990; Marichal, 1992, 2014). En su calidad de enfant terrible americano, tanto en Londres y Paris estrechó lazos con esos latinoamericanos, rentó una habitación con servidumbre y se hizo de una amante francesa. Por supuesto, la oeconomía patriarcal de su padre había muerto con él.

Sumado a eso perteneció al conglomerado de patriotas latinoamericanos, banqueros y especuladores que invirtieron en la minería americana desde la bolsa londinense. Tal sector era visto como la fuente de riqueza inmediata para las nuevas naciones y como inversión fundamental para los británicos (Marichal, 1992, 2014). En ese tenor, Irisarri aprovechando sus ganancias tanto como diplomático como por la gestión del préstamo británico, fundó y presidió la Guatemala Mining Company y la Potosí, La Paz and Peruvian Mining Assocation junto a otros. (Marichal, 1992). Considerando los precedentes de creación de redes de su padre y sus asociaciones políticas, es factible que la inversión en la minería haya sido en función de vínculos familiares en Centroamérica y redes personales creadas en Sudamérica durante sus viajes. En ese sentido:

A fines de 1824 esta compañía necesitaba de dos cosas: inversionistas británicos y centroamericanos, y el visto bueno del gobierno federal. [...] La aprobación gubernamental sólo se otorgó el 28 de julio de 1825 , y las patentes necesarias sólo llegaron a manos de Irisarri el 17 de febrero de 1826. Mientras tanto, por supuesto, sobrevino el trastorno del mercado en Londres en 1825 , y se hundió a consecuencia de él [este proyecto para Centroamérica] (Browning, 1986, p. 120).

En todo caso, sus iniciativas al gestionar el préstamo, su modo de vida y sus negocios particulares le granjearon el rechazo chileno. Estando residiendo en Inglaterra, fue aislado políticamente cuando fue reemplazado por otro diplomático, lo que era ya muy mal agüero para su futuro político. (Browning, 1986; Donoso, 1966; Marichal, 1992, 2014).

Lo peor sucedió en 1825, cuando estalló una crisis-financiera. En la bolsa londinense estalló una burbuja inflada por los bonos latinoamericanos y la confianza en esas inversiones. En ese contexto Irisarri fue acusado en la prensa londinense de malversación de los fondos, por lo que nuevamente fue a juzgados (Browning, 1986; Dawson, 1990). Aunque logró defenderse con éxito en el juzgado, Antonio José ya había perdido el apoyo diplomático chileno. Ante eso prefirió regresar a Centroamérica. Hizo escala en Nueva York para gestionar fondos para fundar un banco en Centroamérica, pero al llegar a las Provincias Unidas de Centroamérica la situación política auguraba tam- 
bores de guerra (Browning, 1986). En sus palabras: "Llegué a Centroamérica a la hora de freír los huevos y me quemé lindamente con la mantequilla que otros habían derretido" (Donoso, 1966, p. 137).

Centroamérica había transitado a la independencia, pero a causa de tensiones políticas estalló la Primera Guerra Federal (1826-1829). Por una parte, estaba un bando centralista nucleado alrededor de la familia Aycinena y el presidente federal Manuel José Arce. Y, por otra parte, los federalistas liderados por otras élites de Nicaragua, Honduras y Nicaragua que tuvieron en Francisco Morazán y el Ejército protector de la Ley a su principal fuerza militar (Taracena Arriola, 2015.)

Como miembro de las redes familiares mejor conectadas, fue designado por Mariano Aycinena, Jefe de Estado de Guatemala en ese momento, como Comandante en Jefe de las operaciones del Estado (Browning, 1986). Se desempeñó como oficial del bando centralista y hacia 1828, fue enviado a Los Altos para organizar el batallón de Quetzaltenango como retaguardia de la Ciudad de Guatemala (Taracena Arriola, 2015). Para ello exigió contribuciones fiscales y hombres en la región, incluyendo a los pueblos indígenas, según la propuesta centralistas de reclutar a indígenas (Sarazúa Pérez, 2013), y seguramente por su experiencia en la guerra de Chile. Pero, en consonancia a su cultura política anti fiscal, la población k'iche' se negó o huyó. Irritado, Irisarri. mandó a quemar el pueblo de San Andrés Xecul. Esa acción áspera e inmisericorde eventualmente marcó su derrota cuando en 1829 sus fuerzas fueron vencidas en los linderos con Soconusco luego de la capitulación de Aycinena ante Morazán en Guatemala (Taracena Arriola, 2000). Antonio pasó varios meses en prisión junto a otros oficiales serviles hasta que varios de ellos fueron expulsados de Centroamérica según el decreto del 22 de agosto de 1829 , entre los cuales también se hallaba su hermano menor Juan Francisco (Montúfar, 1933). Sin embargo, lo notable es que pese al decreto que le enviaría al destierro, pasó varios meses en prisión hasta que escapó de su prisión de San Salvador a bordo de una embarcación británica a inicios de 1830 (Donoso, 1966).

$\mathrm{Su}$ escape le llevó a Guayaquil para posteriormente pasar a Chile, ser intendente y participar, nuevamente como diplomático, en la conflagración entre ese país y la Confederación peruana-boliviana. Ante el triunfo chileno decidió volver a Guayaquil y pasar a Nueva Granada en 1845. Allí construyó una trayectoria entre la literatura y la política en Colombia. Siguió su periplo por Venezuela, Puerto Rico, Cuba y finalmente Nueva York en 1855. Fue electo embajador plenipotenciario de Guatemala y El Salvador en Estados Unidos, gestionando la diplomacia contra William Walker y luego solo representando a Guatemala desde 1863. Finalmente murió en 1865 (Browning, 1986). Si bien su vida luego del exilio en Centroamérica merece una atención mayor, ello rebasa los límites actuales de este artículo y también ha sido precisamente el objeto de estudio de obras ya señaladas arriba.

Un factor evidente al analizar la vida de José Antonio, es que su gran trayectoria se hizo sobre la base relacional construida por su padre. Sin embargo, las orientaciones de las decisiones en la nueva generación cambiaron los objetivos de esos capitales relacionales hacia los esfuerzos revolucionarios. Destacan dos decisiones. Por una parte, el repliegue sobre los vínculos relacionales su parentela extendida, pero solo en la plaza comercial más redituable: Santiago de Chile. Por otra, la apuesta por las finanzas sobre las actividades mercantiles, lo cual puede ser un reflejo de los avatares económicos de José Antonio. El hecho de iniciarse en el cobro de deudas y orientarse a la joven plaza financiera londinense no parece un cambio radical, sino la evolución de una trayectoria.

\section{Reflexiones finales: Vidas paralelas en la formación del capitalismo atlántico y una burguesía americana}

Las trayectorias económicas de los Irisarri reflejan la experiencia de dos generaciones que fueron a su modo revolucionarias y fueron revolucionadas por el contexto mercantil y político de su época. Los cambios en los ciclos económicos en el mundo atlántico, las crisis políticas que a su vez se convirtieron en oportunidades económicas de alto riesgo, la constante interacción con sus pares en escenarios ilustrados y altamente politizados

Pero, mientras más cambiaron las cosas, más quedaron iguales. Las redes familiares, las compañías mercantiles, las operaciones financieras y la fortuna, delinearon las trayectorias de padre e hijo. Ambos ilustran el rol mercantil y financiero que permeó en las relaciones sociales de las élites hispanoamericanas donde la agencia Juan Bautista y Antonio José estuvo mediada por lealtades construidas alrededor de ideales sociales y políticas y por rivalidades forjadas por rivalidades económicas y proyectos políticos. Si bien 
estas situaciones son moneda en escenarios locales y regionales, lo notables es considerar que los mismos se manifestaron en la plataforma atlántica y a nivel continental americano.

En ese sentido es importante señalar una reflexión en torno al rol que jugaron los acontecimientos y protagonistas del reino de Guatemala y las Provincias Unidas de Centroamérica en el devenir de la era de las revoluciones. Una buena muestra de ello son las operaciones que Juan Bautista Irisarri desarrolló a lo largo de la fachada continental del Pacífico y los enlaces que tuvo con la Nueva España y los Estados Unidos hacia el norte. Por otra parte, Antonio José de Irisarri, en sus andanzas entre deudas, diplomacia y participación política y financiera nos sugiere también el devenir de los cambios de la época, y cómo las jóvenes naciones se ligaron a un devenir globalizado dominado por los mercados financieros europeos y paulatinamente norteamericano.

Respecto a los cambios acaecidos durante las revoluciones de independencia el más notable fue el cambio del epicentro financiero y por ende de dominación política. Tanto los estudios de Marichal (1992), Tutino (2016) y Cano Borrego (2018), han dejado claro que, tanto a nivel continental como global, Nueva España se desempeñó como el epicentro global de riqueza gracias a sus minas de plata que eran la fuente de la moneda de cambio para lugares tan dispares como la dinastía Quing en China y los Estados Unidos. Pero, al observar la experiencia de Antonio José, queda claro de las élites americanas buscaron a las potencias europeas para financiar proyectos económicos que sirvieran de base para el progreso y la construcción de las jóvenes naciones.

¿Por qué sucedió eso? Responder ello va más allá del alcance de este trabajo, pero es posible dilucidar dos respuestas. Por una parte, el auge minero novohispano llegó a su punto más alto en 1810, el mismo año en que inició la rebelión de Hidalgo que integró a un conglomerado humano que arraso con las minas que producían tal riqueza y que, a su vez, era el nervio de los mercados financieros de Nueva España, el sostén económico de la Monarquía. Por aparte, la decisión de romper con la monarquía tuvo por consecuencia un vacío institucional económico que impulsara estatalmente la generación de riqueza, premio y manzana de la discordia entre las élites hispanas en el continente. En ese sentido, aparte de los ideales liberales y constitucionales, Francia y Gran Bretaña se perfilaron como las potencias capaces de suplir esa ausencia a través de sus aparatos financieros.
Además, son notables los esfuerzos de hace Irisarri en Londres y Nueva York al buscar capitales para compañías mineras y bancarias. Ello indica una escasez de capitales locales en América. Seguramente ello fue resultado de la descapitalización provocada por la Consolidación de Vales Reales (Marichal, 1992) y los efectos destructivos de las guerras insurgentes. Las urbes anglosajonas, por otra parte, se revelaron como plazas fuertes para obtener los fondos y finanzas tan necesarios para el temprano capitalismo criollo.

Entonces ¿Cómo entra la reflexión sobre la burguesía en estas líneas? Si bien el análisis de la burguesía es algo que parece haber sido "superado" o "pasado de moda", la noción de una clase constituida en un escenario global y con una agencia proporcional entre los siglos XVIII y XIX es parte de la realidad histórica. No obstante, dicha noción por lo común se atribuye solamente a los hombres de las naciones europeas decimonónicas. Pero $¿ Y$ si en realidad dicho grupo social de burgueses-gentilhombres se constituyó primero dentro de una monarquía planetaria como la española? Un análisis teórico fundado en el materialismo histórico no puede caber aquí de momento. Por lo pronto el caso que nos compete sirva quizá como punto de reflexión sobre este grupo social.

El caso de los Irisarri nos permite dilucidar varias características que serán típicas de la burguesía decimonónica. Por una parte, la gran atención al control simultáneo de comercio y política tanto dentro del ámbito "nacional" como en la palestra internacional. Al interior de sus operaciones mercantiles, la centralidad de una "empresa familiar" es un resultado de la combinación de estrategias. Es decir, la necesidad de un grupo social regional en la monarquía y la amalgama de apoyo en operaciones de transporte, resolución de disputas y el fortalecimiento de alianzas dinásticas por uniones consanguíneas. Asimismo, no hay que olvidar que las élites hispanoamericanas no fueron nunca un grupo homogéneo en sus aspiraciones, intereses o criterios. Las luchas entre proyectos políticos republicanos, por el control de operaciones mercantiles o la diferencia entre el reconocimiento que la población indígena es la generadora de riqueza y su destrucción entre una y otra generación, nos habla de contradicciones de una clase sustentada más en la economía mercantil que en la mera propiedad inmueble.

Sería necesario revisar el carácter de dichas élites desde el análisis de sus actividades económicas y no limitarlas a un solo sector. Vale recordar a un Juan Bautista Irisarri no solo comerciante, sino que también 
fue mercader de alcance continental y ganadero provincial. De la misma manera que Antonio José no solo cobraba deudas, sino que fue militar y diplomático.

Finalmente, los Irisarri revelan el peso de una generación sobre otra. Juan Bautista creó lazos para el desarrollo de sus operaciones por los dominios españoles cuyo epicentro financiero fue Nueva España. Antonio José recorrió esos dominios con la salvedad que los nuevos ejes financieros fueron Londres, Paris $\mathrm{y}$, de forma muy incipiente, Nueva York. El hijo caminó sobre las huellas de su padre, de tal manera que pareciese que cargó el peso del fantasma de su padre hasta el fin de sus días. ¿Qué mejor muestra podría existir sobre la existencia histórica de un patriarcado intergeneracional, pese a las picardías de los énfats terribles?

\section{Referencias}

Arrioja, L., Sánchez, C., \& Sánchez, J. (2017). Un acercamiento al abasto de la carne en la Oaxaca colonial y republicana. En E. Quiroz (Coord.), Integración y desintegración del espacio económico mexicano: Mercado interno y abastecimiento de las carnes desde la colonia al siglo XIX (pp. 203-238). Instituto Mora.

Arroyo, L. (30 de enero de 2007). Redes de influencia: Relaciones privilegiadas en el comercio colonial a finales del siglo XVIII: Los Marticorena y su correspondencia epistolar. Nuevo Mundo Mundos Nuevos. https://doi.org/10.4000/nuevomundo. 3213

Balmori, D., Voss, S., \& Wortman, M. (1984). Notable Family Networks in Latin America. The University of Chicago Press.

Batres Jauregui, A. (1896). Literatos guatemaltecos: Landivar e Irisarri, con un discurso preliminar sobre el desenvolvimiento de las ciencias y las letras en Guatemala. Tipografía Nacional.

Belaubre, C. (21 de septiembre de 2005a). Llano, Ambrosio. Asociación para el Fomento de los Estudios Históricos en Centroamérica. https://www. afehc-historia-centroamericana.org/index_action_fi_aff_id_707.html

Belaubre, C. (10 de diciembre de 2005b). Irisarri, don Juan Bautista. Asociación para el Fomento de los Estudios Históricos en Centroamérica. https:// www.afehc-historia-centroamericana.org/index action_fi_aff_id_719.html

Bertrand, M. (2000). Esta Audiencia es toda una sodoma y sicarismo. Complots, trahisons et crise politique fin de siècle à Guatemala. Trace, (37), 74-85.

Bertrand, M. (2005). Las elites sociales de Guatemala en vísperas de la Independencia: Estructuras y dinamismos internos. En I. Álvarez y J. Sánchez (Ed.), Visiones y revisiones de la Independencia Americana: México, Centroamérica y Haití (pp. 37-59). Ediciones Universidad de Salamanca.

Bertrand, M. (2007a). Guatemala City Social Elites on the Eve of Independence: Internal Structures and Dynamics. En J. Dym y C. Belaubre (Ed.), Politics, economy, and society in Bourboun Central America 1759-1821 (pp. 239-263). University Press of Colorado.

Bertrand, M. (2007b). Poder, negocios y familia en Guatemala a principios del siglo XIX. Historia Mexicana, 56(3), 86-917.

Bertrand, M. (2012). De la familia a la red de sociabilidad. Páginas, Revista Digital de la Escuela de Historia, 4(6), 47-80. https://doi.org/10.35305/ rp.v4i6.94

Bonialian, M. (2017a). Comercio y atlantización del Pacífico mexicano y sudamericano: La crisis del lago indiano y del Galeón de Manila, 1750-1821. América Latina en la Historia Económica, 24(1), 7-36. https://doi.org/10.18232/alhe.v24i1.791

Bonialian, M. (2017b). México: De epicentro a periferia. La desintegración del modelo semiinformal del comercio hispanoamericano (17501840). Historia Mexicana, 67(1), 61-123. https:// doi.org/10.24201/hm.v67i1.3441

Bordieu, P. (2011). La ilusión biográfica. Acta Sociológica, (56), 121-128. http://dx.doi.org/10.22201/ fcpys.24484938e.2011.56.29460

Browning, J. (1986). Vida de ideología de Antonio José de Irisarri. Editorial Universitaria.

Cano Borrego, P. D. (2018). La moneda castellana en España e Indias y su proyección internacional: De Carlos II a Carlos III [Tesis de doctorado, Universidad Complutense de Madrid]. https:// eprints.ucm.es/id/eprint/50006/ 
Chambers, S. (2015). Families in War and Peace: Chile from Colony to Nation. Duke University Press.

Dawson, F. (1990). The first latin American debt crisis. ThecCity of London and the 1822-25 Loan Bubble. Yale University Press.

Donoso, R. (1966). Antonio José de Irisarri, escritor y diplomático, 1786-1868. Universidad de Chile.

Dym, J. (2006). From sovereign villages to national states city, state, and federation y Central America, 1759-1839. University of New Mexico.

Fernández, B. (1993). El Reino de Guatemala durante el Gobierno de Antonio González Saravia, 1801 1811. Comisión Interuniversitaria Guatemalteca de Conmemoración del Quinto Centenario del Descubrimiento de América.

Fernández, J. (2003). Pintando el mundo de azul: El auge añilero y el mercado centroamericano, 1750-1810. Dirección de Publicaciones e Impresos, Consejo Nacional para la Cultura y el Arte.

García Giráldez, M. (1993). La emigración vasca a Centroamérica 1750-1800. Las redes familiares como estructuras de poder en Guatemala [Tesis doctoral inédita]. Universidad Autónoma de Madrid.

González Galeotti, F. R. (2020). Comercio franco y mercaderes en la Carrera de Guatemala (17401822) [Tesis de doctoral inédita]. El Colegio de Michoacán.

Hausberger, B. (2011). Limpieza de sangre y construcción étnica de los vascos en el imperio español. En N. Böttcher, B. Hauberger y M. S. Hering Torres (Coords.) El peso de la sangre. Limpios, mestizos y nobles en el mundo hispánico (pp. 29-64). El Colegio de México. https://doi.org/10.2307/j. ctv47wf6r.4

Imízcoz, J. M., \& Guerrero, R. (2004). Familias en la Monarquía. La política de las familias de las elites vascas y navarras en el Imperio de los Borbones. En J. M. Imízcoz (Ed.) Casa, familia y sociedad (País Vasco, España y América, siglos XV-XIX) (pp. 177-238). Servicio Editorial, Universidad del País Vasco.

Irisarri, J. A. (1961). El cristiano errante. Bibliófilos mexicanos.
Irisarri, J.A. (1937). Los diplomáticos sudamericanos en Europa en 1820, juzgados por J.A.

Irisarri. Anales de la Academia de Geografía e Historia, 4, (458-460)

León Saénz, J. (2006). Movimiento marítimo anual por la costa del Pacífico de Centroamérica [Base de datos]. Diálogos, Revista Electrónica de Historia, 6(2). https://doi.org/10.15517/dre.v6i2.6221

Luján Muñoz, J. (1992). Los vascos en el Comercio del Reino de Guatemala al final del Período colonial. Anales de la Academia de Geografia e Historia de Guatemala, 66, (9-16).

Machuca Gallegos, L. (2007). Comercio de sal y redes de poder en Tehuantepec durante la época colonial (Publicaciones de la Casa Chata). Centro de Investigaciones y Estudios Superiores en Antropología Social.

Marichal, C. (1992). Historia de la deuda externa de América Latina. Sociedad Quinto Centenario.

Marichal, C. (2014). Historia mínima de la deuda externa de Latinoamericana. El Colegio de México.

Martínez del Cerro González, V. E. (2006). Una comunidad de comerciantes: Navarros y vascos en Cádiz (Segunda mitad del Siglo XVIII). Junta de Andalucía, Consejo Económico y Social de Andalucía.

Martínez Peláez, S. (2012). La patria del criollo. Ensayo de interpretación de la realidad colonial guatemalteca. Fondo de Cultura Económica.

Montúfar, M. (1933). Papeles del ochocientos: Correspondencia y diario de don Manuel Montúfar, exiliado por la revolución de 1829. Los ordenó José Arzú. El Imparcial.

Palma Murga, G. (1985). Agriculture, commerce et societe au royaume de Guatemala 1770-1821 [Tesis doctoral inédita]. École des Hautes Etudes en Sciences Sociales.

Payno, M. (1861). El hombre de la situación. Imprenta de Juan Abadiano.

Real Academia de la Historia. (s.f.). José Ortiz de la Peña. http://dbe.rah.es/biografias/34548/jose-ortiz-de-la-pena

Rubio, M. (1977). Historia del puerto de la Santísima Trinidad de Sonsonate o Acajutla. Editorial Universitaria. 
Rubio, M. (1979). Alcaldes mayores: Historia de los alcaldes mayores, justicias mayores, gobernadores intendentes, intendentes corregidores, y jefes políticos, de la Provincia de San Salvador, San Miguel y San Vicente (Vol. 2). Ministerio de Educación, Dirección de Publicaciones.

Santos Pérez, J. M. (1999). Élites, poder local y régimen colonial: El cabildo y los regidores de Santiago de Guatemala 1700-1787. Servicios de publicaciones de la Universidad de Cádiz, Plumsock Mesoamerican Studies y Centro de Investigaciones Regionales de Mesoamérica.

Sarazúa Pérez, J. C. (2007). Territorialidad, comercio y conflicto al Este de Guatemala: Santa Rosa, 1750-1871 [Tesis de licenciatura, Universidad de San Carlos de Guatemala]. http://biblioteca.usac. edu.gt/tesis/14/14_0375.pdf

Sarazúa Pérez, J. C. (2013). Recolectar, administrar y defender: La construcción del Estado y las resistencias regionales en Guatemala, 1800-1871 [Tesis doctoral, Universitat Pompeu Fabra]. https:// www.tdx.cat/handle/10803/129811\#page=1

Suárez Argüello, C. E. (2007). La quiebra de una casa de conductas novohispana en los inicios del siglo XIX: Sus causas. Historia Mexicana, 56(3), 817862.

Taracena Arriola, A. (2000). Invención criolla, sueño ladino y pesadilla indígena: Los Altos de región a estado, 1740-1871. Centro de Investigaciones Regionales de Mesoamérica.

Taracena, L. P. (2015). ¿Guerra estatal o guerra de ciudades? Movilización militar, recaudación y discurso político, 1826-1829. En A. Taracena Arriola (Ed.) La Primera Guerra Federal Centroamericana 1826-1829. Nación y estados, republicanismo violencia (pp. 1-56). Cara Parens.

Tutino, J. (2016). Creando un nuevo mundo. Los origenes del capitalismo en el Bajío y la Norteamérica española. Fondo de Cultura Económica, El Colegio de Michoacán, Universidad Intercultural del Estado de Hidalgo.

Woodward, R. (1981). Privilegio de clase y desarrollo económico Guatemala: 1793 a 1871. EDUCA.

Zamora, R. N. (2012) La oeconomía y su proyección para el justo gobierno de la república, San Miguel de Tucumán durante el siglo XVIII. Revista de Historia del Derecho, (44), 201-214.
Zúñiga Diéguez, G. A. (2020). Pensamiento y obra de Antonio José de Irisarri. Intelectual del siglo XIX en América.

\section{Referencias de archivos}

Archivo General de Centroamérica, (AGCA), Guatemala

AGCA, Signatura A1.20, Legajo 928, Expediente 9421, Protocolo de Miguel González, folios 92v-93v. Obligación de 17871. 1 1 $1 / 2$ pesos de Don Juan Jacinto Herrera a favor de Don Juan Baptista de Yrizarri, 14 de mayo de 1785.

AGCA, Signatura A1.20, Legajo 1344, Expediente 9835, Protocolo de Antonio Santa Cruz, folios 1v2., obligación de 16777-7 1/2 pesos de Don Juan Jacinto Herrera a favor de don Juan Baptista de Yrizarri, 12 de enero de 1787.

AGCA, Signatura A2.2., Legajo 197, Expediente 4015 , Contra tres salteadores de caminos no conocidos que robaron una petaca con 486 gruesas de cuerdas de guitarra y violín, 1801.

AGCA, Signatura A1.15, Legajo 2530, Expediente 20159 Sebastián Melón sobre la declaratoria de la sentencia de arbitrios en los autos contra Juan Bautista de Irrisarri por unas resmas de papel, 1802.

AGCA, Signatura A1.20, Legajo 766, Expediente 9259, Protocolo de José María Estrada, Folios 6566v, poder general de Don Juan Bautista de Irisarri a favor de Don Juan Felipe Xaurnaga vecino del Puerto de Veracruz, 23 de mayo de 1800.

AGCA, Signatura A1.20, Legajo 766, Expediente 9259, Protocolo de José María Estrada, Folios $79 \mathrm{v}-80 \mathrm{v}$, poder general de Don Juan Bautista de Irisarri a favor de Don Francisco de Sosa en el Puerto de Trujillo y Don Thomas Urdiros, 7 de junio de 1800.

AGCA, Signatura A1.20, Legajo 766, Expediente 9259, Protocolo de José María Estrada, Folios $184 \mathrm{v}-185 \mathrm{v}$, poder general de Don Juan Bautista de Irisarri a favor de Don Antonio de Bernabé y Madero vecino de Cádiz, 21 de noviembre de 1800. 


\section{Archivo Histórico de Guayas (AHG), Guayas, Ecuador}

AHG, EP/J 555.

Archivo Histórico de las Notarías del Estado de Oaxaca (AHNEO), Oaxaca, México

Archivo Histórico de las Notarías del Estado de Oaxaca [AHNEO], Libro 74, Protocolo de Joseph Álvarez, Folio 329v, poder especial de Francisco Antonio de Goytia, apoderado de Juan Bautista de Irisarri a favor de Gabriel de Iturbe e Yraeta, 23 de diciembre de 1800 .

Archivo Histórico Diocesano de San Cristóbal de las Casas (AHDSCC), Chiapas, México

AHDSCC, Ramo Correspondencia, Expediente 60, Carpeta 5139, Carta de Antonio José de Irisarri a Ambrosio el Llano, México 25 de mayo de 1806.

AHDSCC, Ramo Correspondencia, Expediente 60, Carpeta 5140, Carta de Antonio José de Irisarri a Ambrosio del Llano, 9 de agosto de 1806.

\section{Archivo de la Compañía de Francisco de Yraeta (ACOFY), México}

ACOFY, 2.1.34. Carta de Ignacio Iturbe Yraeta para Francisco de Goytia, Folios 419-420v, 27 de diciembre de 1800.

ACOFY, 2.1.34. Carta de Iturbe Yraeta para Francisco de Goytia, Folios 415-415v, 31 de diciembre de 1800.

ACOFY, 2.1.38. Carta de Gabriel Iturbe Yraeta para Juan Bautista de Irisarri, Folios 163-164, 24 de octubre de 1801.

ACOFY, 2.1.38. Carta de Gabriel Iturbe Yraeta a Juan Bautista de Irisarri, Folios 221-222, 25 de noviembre de 1801.

ACOFY, 2.1.43. Carta de Gabriel de Iturbe Yraeta a Antonio José de Irisarri, folio 249, 22 de noviembre de 1806.
ACOFY, 2.1.43. Carta de Gabriel de Iturbe Yraeta a Antonio José de Irisarri, Folio 348v-349, 25 de febrero de 1807. 